\title{
Reaching a milestone
}

\author{
Marek Szpalski · Robert Gunzburg • \\ Max Aebi
}

Published online: 27 August 2014

(c) Springer-Verlag Berlin Heidelberg 2014

Summertime is a time of vacation and relaxation for most people but also a period which triggers a certain level of anxiety among scientific journal editors. Indeed, June/July is the time when Thomson Reuters ISI web of knowledge (formerly Institute for Scientific Information) releases the Impact Factors calculated from the previous year data. As a reminder, the impact factor (IF) is the oldest and most known journal metric for scientific publications published yearly since 1975 . It is calculated every year by dividing the number of journal articles cited during the 2 previous years by the total number of papers published in that journal during those 2 years. Basically it can be considered as the average number of citations received per paper published in that journal during those 2 years. Each scientific field has its own IF ranking list. Scopus has a similar metric called impact per publication (IPP) but calculated on three consecutive years instead of two and, not surprisingly, values for a given publication of IF and IPP are pretty close.

Over time IF took an increasing importance in assessing journal and then individual scientists value in the academic world. Many universities and scientific institutions assess

\footnotetext{
M. Szpalski $(\bowtie)$

Department of Orthopedics, Iris South Hospitals, 1180 Brussels, Belgium

e-mail: mszp@skynet.be

R. Gunzburg

Cavell Spine Centre, Edith Cavell Clinic,

Edith Cavell Street 32, 1180 Brussels, Belgium

e-mail: robert@gunzburg.be

M. Aebi

Orthopaedic Department, Hislanden Salem Hospital,

3000 Bern 25, Switzerland

e-mail: max.aebi@MEMcenter.unibe.ch
}

resumes in a mathematical way based on the researchers publications' IF. Furthermore, a number of academic institutions strongly "encourage" their faculty to publish in journals ranked within the best $20 \%$ IF ranking in their field if they want to have their publications taken into consideration for advancement or grant financing. Although strong criticisms are regularly voiced, among others about the reliability of calculation [1] or skewing of results by one or a very small number of highly cited papers [2], IF remain the de facto gold standard for the evaluation of a scientific journal.

The editors of this journal had, therefore, a good summertime as European Spine Journal received the best Impact Factor of its 23 years of existence. Our IF of 2.473 ranks us 12th out of 67 orthopedic journals (which also includes, for reasons known only to ISI, physical therapy publications). We are now number two of journals dedicated to spine and very close to The Spine Journal which is ranked 11th. It is very interesting to see that the most important publications in the field of spine are very close in their rankings, The Spine Journal 2.800, European Spine Journal 2.473, Spine 2.447, Journal of Neurosurgery-Spine (listed in the surgery section) 2.355 and Journal of Spinal Disorders and Techniques a bit further at 1.888. They are the only spine publications currently ranked. This "gang of five" will probably grow in the future as the field of spine specific journals is getting crowded, Asian Spine Journal, Global Spine Journal, Evidence Based Spine Care Journal, Open Spine Journal, International Journal of Spine Surgery and probably others are eager to join the club [3].

In the growing field of bibliometrics, other assessment methods competing with IF, and presented as more valid, have been developed. Thomson Reuters ISI itself has introduced the Eigenfactor which takes in account not only the number of citations but the ranking of the citing 
journal, thus a citation in a highly ranked journal will have more weight than one in a lower ranked one [4] and European Spine Journal is ranked 8th out of 67 in that classification.

Scopus also assesses the percentage of cited papers among those published. For spine journals, that percentage varies from 60 to $69 \%$ and European Spine Journal is second with $65 \%$ of published papers cited.

The $\mathrm{H}$ index is increasingly used to measure the productivity and impact of individual scientists but it can also be applied to journals. H Index is the number of papers of an individual or a journal, which has been cited at least the same number of times than that number of papers. $H$ index of our journal is 81 ; this means that 81 papers published in the journals have been cited at least 81 times each, the journal is 17 th out of 219 journals in the field of orthopedics, sport medicine, bone, cartilage and muscle journals and second in the spine field.

Finally, scientific research tends to become increasingly collaborative and international and in that aspect our journal is the most "international" in the spine field as $16.3 \%$ of papers featured authors from 2 or more countries, the other spine journals ranging from 9.3 to 14.6.
We are very proud of this achievement due to the hard work and commitment of current and past Editors and members of the Editorial Board and to our loyal pool of reviewers whom we thank for their great reviewing work which enables us to publish papers of increasing quality and continue to move forward.

Conflict of interest None.

\section{References}

1. Rossner M, Van Epps H, Hill E (2007) Show me the data. J Cell Biol 179:1091-1092

2. Editorial (2005) Not-so-deep impact. Research assessment rests too heavily on the inflated status of the impact factor. Nature 435:1003-1004

3. Aebi M, Szpalski M (2014) The growth and increase of the number of journals focusing on spine: a scientific blessing? Eur Spine J 23:491-492

4. Bergstrom CT, West JD, Wiseman MA (2008) The Eigenfactor ${ }^{\mathrm{TM}}$ metrics. J Neurosci 28:11433-11434 